\title{
STABILIZATION OF LEAD IN INCINERATION FLY ASH BY AGEING AND CARBONATATION IN CONTACT WITH MOISTURE AND AIR
}

\author{
R. SJÖBLOM ${ }^{1}$, A. ZIETEK ${ }^{2}$, E. GAUDE ${ }^{3}$, J. FAGERQVIST ${ }^{4} \&$ K. KARLFELDT FEDJE ${ }^{5}$ \\ ${ }^{1}$ Waste Science \& Technology, Luleå University of Technology, Luleå, Sweden / Tekedo AB, Nyköping, Sweden. \\ ${ }^{2}$ Jönköping Energi AB, Jönköping, Sweden. \\ ${ }^{3}$ Miljöhantering i Jönköping AB, Jönköping, Sweden. \\ ${ }^{4}$ Avfall Sverige - Swedish Waste Management and Recycling Association, Malmö, Sweden. \\ ${ }^{5}$ Water Environment Technology, Chalmers University of Technology, Gothenburg, Sweden / Renova AB, \\ Gothenburg, Sweden.
}

\begin{abstract}
Residues from incineration of waste vary considerably in quality not only depending on the composition of the waste and the incineration system, but also on the extent and duration of contact with moisture and carbon dioxide in the atmosphere. Lead has a rather varying abundance and an even more varying availability in ash as determined by leach tests. Fresh fly ash from Jönköping Energi AB has a relatively low content of lead in comparison with other similar ashes but a somewhat high leach rate in relation to the total amount. Thus, in determining the pertinent destinations for this ash, it is appropriate to assess the availability after prolonged contact with moisture and air. It was found that the leaching decreased by up to around three orders of magnitude after such conditioning, which will what take place in a landfill over time. The effect was confirmed by pilot tests. The paper also describes the ash chemistry and possible mechanisms for the stabilization. It is concluded that the stabilization can facilitate landfilling.

Keywords: acceptance criteria, ageing, aragonite, ash, calcium carbonate, carbonatation, hazardous waste, incineration, landfilling, leaching, lead.
\end{abstract}

\section{BACKGROUND}

\subsection{Legislation}

This paper relates to the Swedish legislation on classification of waste as hazardous or nonhazardous as well as the legislation on acceptance for landfilling.

Classification of waste as hazardous or non-hazardous is to be carried out in accordance with the ordinance of waste [1] which is an implementation in Sweden of the EU waste framework directive [2]. Annex III of this directive has recently been replaced by a EU regulation [3].

Classification as hazardous or non-hazardous waste is to be based on the chemical form, i.e. the inherent properties and the associated hazards. Classification of residues from incineration is thus quite complicated, to a large extent due to the complex chemical constituents. Consequently, methods have been developed in order to make such classifications possible in a practical manner $[4,5]$. 
Acceptance of waste to landfilling in Sweden is to be carried out in accordance with the regulation on acceptance criteria [6] issued by the Swedish EPA. It constitutes national legislation under the EU landfill directive [7].

The acceptance criteria [6] are based largely on batch and column leach tests. The test methods are applicable and valid only for such waste that does not react with water, and the regulation states that the leach testing should as far as possible and be feasible refer to equilibrium conditions.

In compliance, a method has been developed for ageing of incineration residues under moist conditions, see [4] and references therein.

There is a criterion in [6] that supplements those of leach tests. Thus, waste that has been classified as non-hazardous may be deposited on a landfill for non-hazardous waste without any leach testing. This presupposes that such waste is not co-deposited with such hazardous waste that can be accepted under the leach criteria. This supplementary criterion is not valid in all EU countries.

In practice, local authorities, to whom results of a classification as non-hazardous waste have been presented, may ask about leach data. Moreover, companies themselves may wonder if depositing waste with high leach rates really can be regarded as being compliant with the general statements in our Environmental Code on protection of health and the environment. A key issue in this regard is, of course, to consider if a high leach rate is a short-term effect or if such leaching will take place even after prolonged contact with water and air.

\subsection{The research question}

The situation just described is presently being experienced by Jönköping Energi AB, whose fly ash might be landfilled locally as non-hazardous waste if the leaching of lead could be tolerated. If not, it might have to be treated and eventually deposited in a landfill for hazardous waste.

This situation prompted the present project, which has been financed by Jönköping Energi AB, Miljöhantering i Jönköping AB and Avfall Sverige - Swedish Waste Management and Recycling Association.

Most of the contaminant elements in incineration residues do not constitute such problems as mentioned above for lead. E.g. elements that can have similar ionic radii as iron, e.g. $\mathrm{Cr}, \mathrm{Ni}, \mathrm{V}$ and $\mathrm{Zn}$, are typically incorporated into iron rich phases by solid solution, thus becoming inaccessible to the pore water. [4, 5] Equivalent effects appear also e.g. in some silicates. $[4,5]$

Arsenic is, in general, one of the contaminants of high interest from a health and environment point of view. It has been shown, however, that arsenic in ash originates almost exclusively from certain impregnated wood, and that it is therefore feasible to separate arsenic containing waste by sorting using x-ray fluorescence (XRF) equipment [8].

This leaves lead and chlorine as the most potent villains in conjunction with landfilling. The full research question in this paper therefore includes these elements.

\section{OBJECTIVES AND SCOPE}

The objectives and scope of the present paper are as follows.

1. To carry out an information search on how lead might become stabilized in ash during ageing and after contact with water and air. 
2. To carry out a similar search with regard to the possibility of removing the chlorides from the ash.

3. To investigate experimentally how the availability of lead may change with ageing in contact with moisture and air.

4. For incineration residues that have been classified as non-hazardous: How disposal at a landfill for non-hazardous waste might be shown to be pertinent also in view of the leaching of lead.

5. For incineration residues that have been classified as hazardous: How disposal at a landfill for hazardous waste or non-hazardous waste might be shown to be pertinent also in view of the leaching of lead and chloride. Possibly, removal of chloride by washing may be much more feasible after (a) lead has been stabilized, and (b) less soluble phases containing chloride have been decomposed. In such a case, the leachant may contain only low levels of the contaminant elements, thus facilitating treatment before release. Similarly, the ash residue may become essentially free from any chlorides.

In addition, some comments will be made regarding the significance (or rather lack of significance) of the speciation of lead for the classification as hazardous or non-hazardous waste.

\section{INFORMATION SEARCH}

\subsection{Fuel, incineration and formation of residues}

The fuel for the incineration originates from private homes as well as from industry and other professional entities. Pure biofuels can also be included as a part of a fuel mix. The fuel consists mainly of organic matter that is incinerated and thereby converted to gaseous compounds. Most of these are released through the stack, but hydrogen chloride and sulphur dioxide are absorbed using lime (calcium hydroxide) in most cases.

Fuels also contain other constituents that appear as solid residues after incineration. Some of these have passed through the process more or less unchanged, whilst others may have been completely converted to other chemical forms.

The residues thus comprise relatively unchanged inorganic constituents from the fuel, actual ash and spent lime (APC Air Pollution Control residues). Major elements in the residues include $\mathrm{O}, \mathrm{Si}, \mathrm{Al}, \mathrm{Ca}, \mathrm{Fe}, \mathrm{Na}, \mathrm{K}, \mathrm{Mg}$ and $\mathrm{P}$. Some of the minor elements are of interest in view of their potentially hazardous forms of occurrence, including $\mathrm{As}, \mathrm{Sb}, \mathrm{Pb}, \mathrm{Cr}, \mathrm{Cu}$ and $\mathrm{Zn}$ (contaminant elements). Further information can be found in [9].

\subsection{Forms of occurrence, major elements}

The residues from incineration appear mostly in oxide form, but some of the cationic elements, especially $\mathrm{Ca}, \mathrm{Na}$ and $\mathrm{K}$, also appear as chlorides and sulphates.

The properties of a residue can vary considerably depending on the origin (unconverted material, 'true' ash, or spent lime) and the exit point as well as on the ageing in contact with moisture and air. Fly ash, in particular, can be very reactive with regard to water and carbon dioxide, especially its glass phase.

The ageing includes hydration and carbonatation. The alterations are in most cases incongruent. The main phases formed as well as the chemistry in general, are governed by the 
composition of the major elements. The $\mathrm{pH}$ is usually high and this implies that also aluminium and silicon in oxide form participate in the alterations. Some further information can be found in [9].

\subsection{Forms of occurrence for minor elements in general}

The potential for contaminant elements to cause harm to health and the environment depends largely on the availability to the water phase, and thus also to their forms of occurrence. They have been investigated using a number of tools and the results have been reported in a large number of scientific publications. When such information is to be evaluated and compiled, it is essential to be well aware of the advantages and limitations of the different methods used, including the following.

$\mathrm{X}$-ray diffraction can be used to identify the crystalline phases involved and, thereby, also largely the chemical composition. However, phases in low abundance may be difficult to investigate. The technique is insensitive to amorphous phases and is therefore of little or no use for glass.

Thermodynamic calculations can include even low levels of minor or trace elements, and results can be checked against e.g. leach data. However, thermodynamic equilibrium is assumed. Thus any metastability, e.g. from phases stable at a high but not at a low temperature, cannot be treated correctly. The same can be said about solid solution where none of the commercially available computer codes include such capabilities. It might be added that solid solubility becomes increasingly important the lower the abundance of the element in question. In addition, a case can be made about the degrees of freedom and the number of variables refined.

Electron microscopy does reflect the actual presence of the various elements as well as their distribution among the different phases. However, the sensitivity might not be sufficient to detect a low level of a trace element in phases formed by the major elements.

EXAFS (extended x-ray absorption fine structure) does 'see' all the atoms of an element, and can be used to identify the different types of bonding present. However, the technique is elaborate and expensive, and few investigations have been carried out on incineration residues. Therefore, one frequently has to resort to investigations made on similar materials and elements.

Comparison can also be made with 'model systems' in which the contaminant elements are present at a higher levels, e.g. in natural minerals. A draw back here might be that solid solution may be efficient at low, but not at high levels, cf. the subsequent discussion on lead in section 3.4.

The conclusion after analyzing a large number of publications is as follows.

Any minor element usually appears in more than one chemical form in any given incineration residue. This may or may not include one or more crystalline phases in which such an element is a major one, but it always - or at least in most cases - includes solid solution.

Solid solution usually takes place in the form of substitution that is governed by Goldsmith's rules [10]. They say that substitution can take place when the difference in size of an atom is less than $15 \%$ and the difference in charge is less than 2 . In addition, the difference in electronegativity should not be too large [10]. The solid solution is driven by the entropy increase on substitution, and the effect is therefore larger, the higher the dilution.

Thus, e.g. Ni, Cr-III, $\mathrm{Cu}$ and $\mathrm{Zn}$ readily go into solid solution in iron-rich phases [11], [section 6.8.5], Fe being a major element in most incineration residues. Accordingly, and since iron-III (hydr)oxides have very low solubility, these contaminant elements usually have 
a low availability to the water phase in aged incineration residues. This includes $\mathrm{Cr}$ where the oxidation number III is stabilized by the solid solution [12].

\subsection{Forms of occurrence for lead}

The situation is, however, less straightforward for lead. Only a few of the elements in incineration residues have ionic radii at around $\pm 15 \%$ or less of that for lead, notably $\mathrm{Ca}, \mathrm{Ba}$ and $\mathrm{K}$. Here, $\mathrm{Pb}$ does not associate itself much with $\mathrm{K}$ due to the difference in electronegativity, and $\mathrm{Ba}$ is not very abundant.

Experimental investigations on fly ash and bottom ash, fresh and aged, have shown, see e.g. [13-23], that lead occurs both as a major element in some phases (minerals) and in the form of solid solution in phases in which calcium is abundant. Lead thus associates itself with calcium as well as iron. The association with calcium includes carbonates, phosphates and ettringite where ettringite may decompose on carbonatation to form sulphates and carbonates.

It has been found that carbonatation may lead to a decrease of the leaching of $\mathrm{Pb}$ by a couple of orders of magnitude, see e.g. [21, 23]. Thus, exposing incineration residues to carbon dioxide may lead to stabilization of any residual lead that might otherwise have been susceptible to leaching, e.g. lead that has been condensed on the ash particles in the low temperature part of a furnace system in the form of chloride [24, 25], or perhaps $\mathrm{CaClOH}$.

It might thus be hypothesized that it is the reaction with carbon dioxide and the stabilization with carbonate that constitute the key to a full stabilization of lead in incineration residues. This is the approach in the present paper for the information search as well as for the experiments. Thus, in the following of the present section, results from surveys of chemical and mineralogical literature are summarized. It is intended that further details, including full references, will be provided in a future journal article.

It is obvious from the above, that for lead, there is a 'competition' between the solid solution alternative and the own mineral one. In this paper own mineral refers to situations in which lead is a major element in a phase.

Thermodynamically, it works as follows. At low concentrations in the pore water, lead goes into solid solution with other minerals, but as soon as a solubility product is exceeded lead will go into its own mineral phases, e.g. cerrusite $\left(\mathrm{PbCO}_{3}\right)$. Moreover, minor elements may have an impact on which phases are formed with the major elements, thus stabilizing certain phases with a high solid solubility (e.g. aragonite) at the expense of phases with low solid solubility (e.g. calcite). Aragonite and calcite both have the formula $\mathrm{CaCO}_{3}$.

In reality, further factors need consideration. Transport (diffusion) of lead may be limited in relation to the availability of carbon dioxide, in which case own mineral phases are favoured. Formation of new phases such as aragonite may take time, especially with regard to nucleation.

Actually, a number of calcium carbonate phases may form, with or without hydrate water, and the following phases are considered: amorphous calcium carbonate, vaterite, calcite and aragonite.

Amorphous calcium carbonate is formed initially, at least sometimes. It is the most unstable of the four phases considered, and crystallizes to any of the other alternatives. For the phases of ideal $\mathrm{CaCO}_{3}$ composition, calcite is the most stable, followed by aragonite and vaterite. The order of stability can be changed by the solid solution, substitution and precipitation conditions, at least for calcite and aragonite. 
The ability to pick up lead in solid solution, i.e. substituting calcium with lead, varies considerably with the size of the position for calcium in the structures Thus, there are nine, eight and six nearest neighbouring oxygen to calcium in the crystal structures of aragonite, vaterite and calcite, respectively. The larger the number of nearest the neighbours, the larger the position. Consequently, lead may substitute at room temperature in aragonite at percentage levels while the substitution may be relatively insignificant in calcite.

Substitution can take place in calcite too, but in this case it is ions that are smaller than calcium that substitute well, especially $\mathrm{Mg}$ and Fe. Consequently, calcite types of crystal structures with $\mathrm{Ca}, \mathrm{Mg}$ and $\mathrm{Fe}$ as major elements may constitute sinks for minor elements similarly to other iron rich phases.

There is a further important difference between the solid solution and own mineral alternatives. In the latter case, the lead content is about the same throughout the grains formed on dissolution and precipitation. However, with solid solution, lead might be drawn out of solution such that the content becomes highest in the middle of the grains, and very low at the surfaces. This may give rise to leach rates that are much lower than those for the cases of own minerals.

\subsection{Forms of occurrence for chloride}

It is frequently assumed that the element chlorine is easily extracted during leaching in the form of chloride. This might not be entirely true, and it has been reported [26] that some of the chlorine can be bonded into less soluble phases e.g. $3 \mathrm{CaO} \cdot \mathrm{Al}_{2} \mathrm{O}_{3} \cdot \mathrm{CaCl}_{2} \cdot 10 \mathrm{H}_{2} \mathrm{O}$, and $3 \mathrm{CaO} \cdot \mathrm{Fe}_{2} \mathrm{O}_{3} \cdot \mathrm{CaCl}_{2} \cdot 10 \mathrm{H}_{2} \mathrm{O}$.

Such phases are broken down on carbonatation, in which case the chloride ions are liberated and can be removed with the wash water.

\subsection{Conclusions for the approach for the experimental work}

The information search has shown that carbonatation can lead to a substantial reduction in the leach rate for lead and to a more or less complete leaching of the chlorides. However, there are many different chemical reactions that take place in incineration residues after contact with moisture, carbon dioxide and oxygen, and there may be several reasons for stabilization.

The search has also clearly indicated that such conditions that favour solid solution should be sought. Thus, carbon dioxide should be added at a slow rate and at a low concentration. Diffusion processes should be supported by assuring an open porosity, but yet there should be sufficient pore water to facilitate dissolution and precipitation. Consequently, this constitutes the basis for the selection of the conditions for the experiments.

\section{EXPERIMENTAL}

Three types of tests were performed: can tests, column tests and pilot scale tests. All tests were carried out using fly ash from the Jönköping Energi AB incineration and district heating plant. Its elemental composition is shown in Table 1. The laboratory tests were carried out using granules in the size range $2-4 \mathrm{~mm}$, and the pilot scale tests were conducted using ash mixed with water. The leach properties were evaluated using batch tests, similar to those prescribed in [6], with a liquid to solid ratio of ten, and with a contact time of 24 hours.

The can tests were carried out primarily in order to determine the feasibility and appropriate conditions for the column test. The following parameters were varied: initial moisture 
content, time and contact with air. The last was varied by keeping some cans closed, others open and yet others kept open for a couple of minutes every other day. All cans were tumbled for about one minute every other day. A total of 18 such tests were made.

The column test was carried out using $328 \mathrm{~g}$ of granules having a water content of $23 \%$. This material was put into a column having a width of $35 \mathrm{~mm}$. Ambient air was sparged into a wash bottle after which it was led through the column. The wash bottle was kept at a temperature somewhat lower than the ambient so that the relative humidity of the air entering the column was about $54 \%$. The flow was around $230 \mathrm{~mL} / \mathrm{min}$. The outgoing air was monitored for moisture and carbon dioxide. The arrangement is shown in Fig. 1.

The still ongoing pilot (June 2016) tests are being conducted as shown in Fig. 2. The idea was to test the carbonatation on a sufficiently large scale and under varying wet and dry conditions, as governed by the changing weather conditions.

Table 1: Elemental composition of the fly ash used in the present work. The major elements are figured as oxides.

\begin{tabular}{lllllllll}
\hline Major elements & $\mathrm{SiO}_{2}$ & $\mathrm{Al}_{2} \mathrm{O}_{3}$ & $\mathrm{CaO}$ & $\mathrm{Fe}_{2} \mathrm{O}_{3}$ & $\mathrm{~K}_{2} \mathrm{O}$ & $\mathrm{MgO}$ & $\mathrm{Na}_{2} \mathrm{O}$ & $\mathrm{P}_{2} \mathrm{O}_{5}$ \\
\hline Abundance, wt- $\%$ & 10.3 & 3.5 & 32 & 2.1 & 1.81 & 1.45 & 3.7 & 0.54 \\
Minor elements & $\mathrm{Sb}$ & $\mathrm{As}$ & $\mathrm{Ba}$ & $\mathrm{Pb}$ & $\mathrm{Cu}$ & $\mathrm{Cr}$ & $\mathrm{Zn}$ & $\mathrm{Cd}$ \\
Abundance, ppm & 757 & 50 & 1050 & 1950 & 630 & 229 & 8620 & 83.1 \\
\hline
\end{tabular}

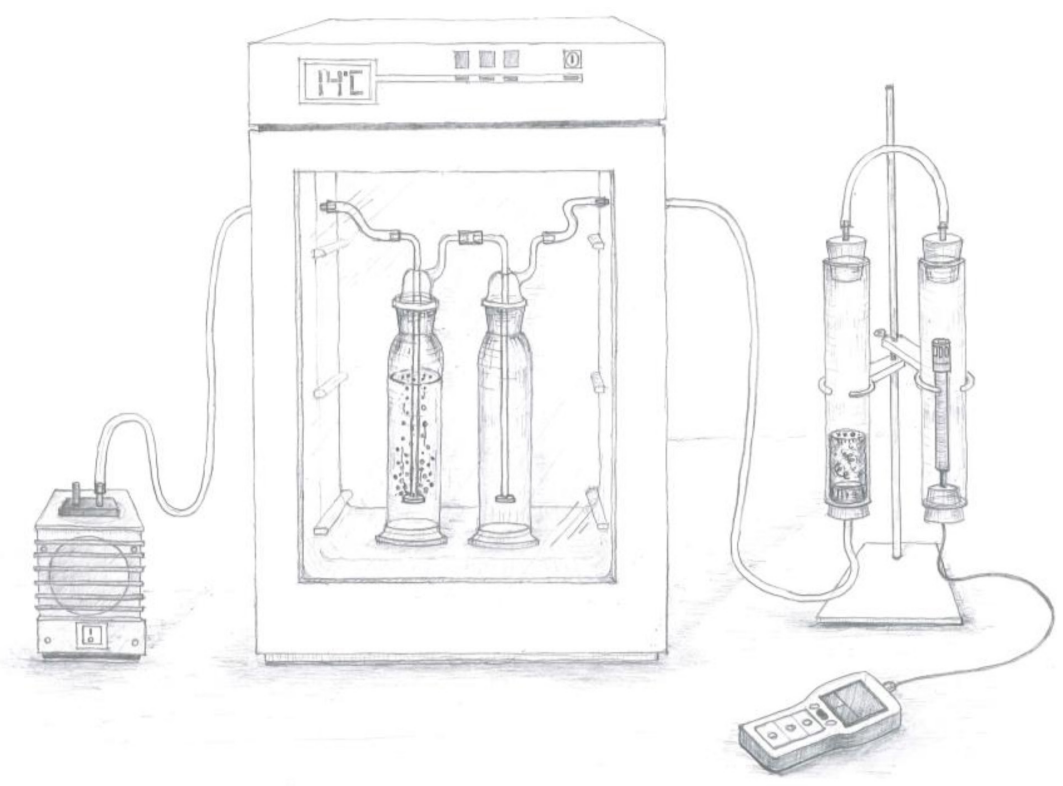

Figure 1: The experimental arrangement for the column test, see text for details. (Illustration drawn by Fabian Sjöblom.) 


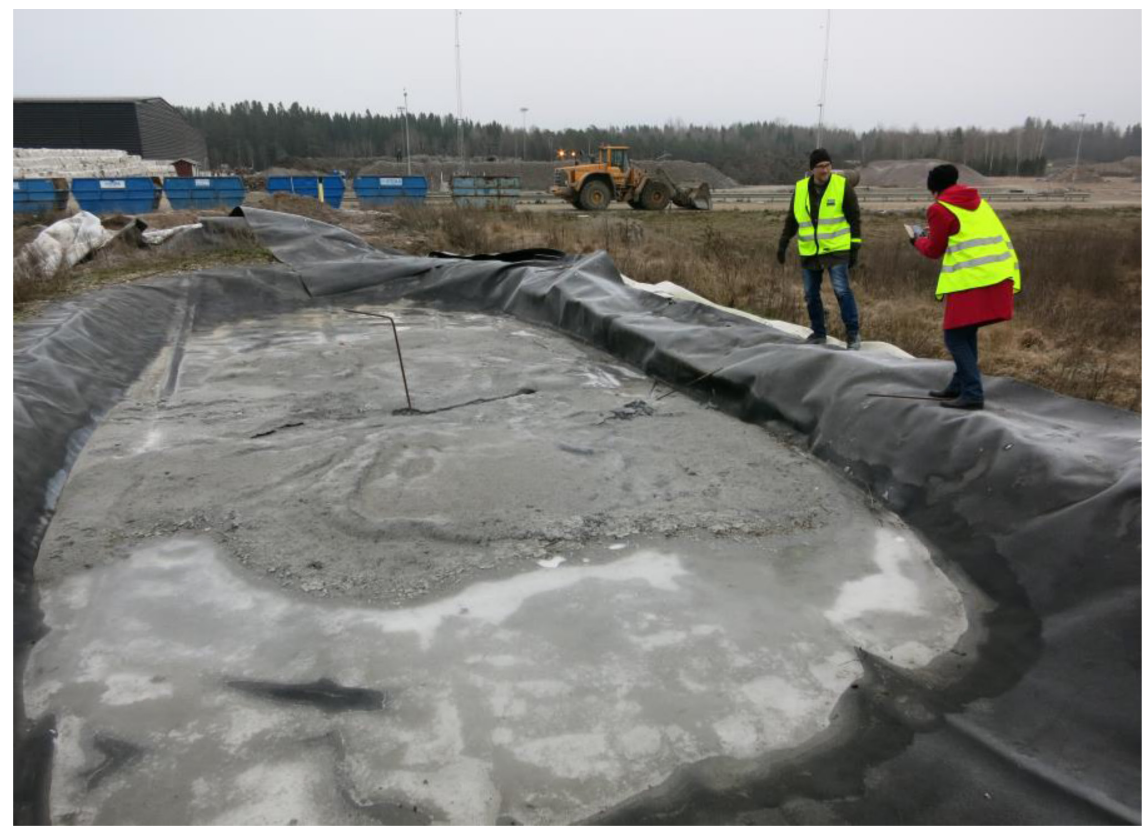

Figure 2: One of the pilot scale tests, see text for details.

\section{RESULTS}

The results of the can tests were roughly as follows. The initial leach rate for lead for a fresh sample was around $750 \mathrm{mg} / \mathrm{kg}$ ash. The moisture content had only a moderate effect. The leach rate for closed cans decreased to around $550 \mathrm{mg} / \mathrm{kg}$ after 23 days, and to around $350 \mathrm{mg} / \mathrm{kg}$ after 174 days. The corresponding figures for incidentally opened cans were around $525 \mathrm{mg} / \mathrm{kg}$ and $300 \mathrm{mg} / \mathrm{kg}$. For constantly open cans, the corresponding figures were around 300 and $1.5 \mathrm{mg} / \mathrm{kg}$, respectively. Thus, carbonatation had a profound effect, while self-curing and oxidation had moderate and inadequate effects. For other ashes studied by one of the authors (Sjöblom), the effect of self-curing with only moisture was found to be much greater, in comparison.

The results from the can tests prompted the initiation of the column test. It was conducted for 39 days with the flow and moisture data given above. The leach rate for lead for the half of the material closest to the air inlet to the column was $0.65 \mathrm{mg} / \mathrm{kg}$, and that for the upper half was 0.89 .

Data so far (April 2016) from the pilot scale tests indicate leaching after 14 months days of $46 \mathrm{mg} / \mathrm{kg}$ at near the surface and $151 \mathrm{mg} / \mathrm{kg}$ at $0,4 \mathrm{~m}$ below the surface.

Actually, the results include data for a number of elements, but that will be analysed and presented later.

\section{CONCLUSIONS, LIMITATIONS AND COMMENTS}

The information search showed that lead in incinerator fly ash can form phases in which lead is a major element as well as be included in the form of solid solution in carbonate and other phases formed by the major elements. The solid solution alternative is preferable in view of its more efficient stabilization. Solid solution can be favoured by time, low concentrations and good transport (diffusion). 
The experiments have shown that the leaching of lead from fly ash from the incinerator at Jönköping Energi AB will decrease with around three orders of magnitude after contact with moisture and air, and may thus, with a large margin (around an order of magnitude), meet any requirements on leaching for disposal at a landfill for non-hazardous waste. This can be useful in conjunction with ash that has been classified as hazardous as well as non-hazardous waste (see sections 1.1 and 2 above).

It might be tempting to conclude that the stabilization of the present ash on carbonatation is due to the formation of solid solutions of lead in carbonates. Although this is clearly what is indicated by the present results, full proof is not provided. Such proof might be obtained, e.g. by electron microscopy in combination with EDX (Energy Dispersive X-ray spectroscopy) and x-ray crystallography. It is not possible to resolve this issue using ordinary thermodynamic calculations, since the commercial programmes available do not include any features that allow calculations on solid solutions.

Another limitation of the present results is that they cannot be used, at least not directly, for the classification of waste as hazardous or non-hazardous. This is because the legislation on classifications of waste as hazardous or non-hazardous lumps together all lead compounds, except for a few that are listed, to certain codes. However, tests may still be carried out in accordance with the legislation [1-3].

Many efforts are presently taken worldwide to wash ash and thereby obtain a material that can either be used at a landfill or deposited on it in a less elaborate manner. The present results indicate that it may be favourable, at least in some cases e.g. when contaminant elements are to be returned to the ash, to first age the ash, and then do the leaching since this will give rise to a better separation of lead and chloride.

Finally, the results indicate that in situ carbonatation might be preferable in comparison to one in a chemical process [26]. In situ carbonatation has been practiced on an industrial scale for decades in order to improve the $\mathrm{Na} / \mathrm{Ca}$ ratio in montmorillonite structures and thereby also the swelling properties of bentonite clays.

\section{REFERENCES}

[1] Ordinance of waste (in Swedish: Avfallsförordningen). SFS 2011:927.

[2] Directive 2008/98/EC of the European Parliament and of the Council of 19 November 2008 on waste and repealing certain Directives.

[3] Commission regulation (EU) No 1357/2014 of 18 December 2014 replacing Annex III to Directive 2008/98/EC.

[4] Sjöblom, R., Classification of waste as hazardous or non-hazardous - the cases of ash and ag. WIT Transactions on Ecology and the Environment, 163, pp. 285-296, 2012.

[5] Sjöblom, R., Classification of ash as hazardous or non-hazardous waste. Crete 4th International Conference, Industrial and Hazardous Waste Management, 2014.

[6] Regulation issued by the Swedish Environmental Protection Agency on landfilling, criteria and proceduress for for receiving waste at facilities for landfilling of waste (in Swedish: Naturvårdsverkets föreskrifter om deponering, kriterier och förfaranden för mottagning av avfall vid anläggningar för deponering av avfall). NFS 2004:10.

[7] Council Directive 1999/31/EC of 26 April 1999 on the landfill of waste.

[8] Sjöblom, R. \& Kumpiene, J., Energy generation by waste incineration: the management of impregnated wood. WIT Transactions on Ecology and the Environment, 195, pp. 89-100, 2015. http://dx.doi.org/10.2495/ESUS150081 
[9] Christensen, T.H., Solid Waste Technology \& Management, John Wiley and Sons, 1, 2011.

[10] Faure, G., Principles and Applications of Geochemistry, 2nd edn, Section 8.1. PrenticeHall International, 1988.

[11] Bodek, I., Lyman, W.J. \& Reehl, W.F., Environmental Inorganic Chemistry, Properties, Processes and Estimation Methods, Pergamon press, 1988.

[12] Callender, E., Heavy metals in the environment - historical trends. In Environmental Geochemistry, ed. B.S. Lollar, Elsevier, 2005.

[13] Wang, L., Chen, Q., Jamro, I.A., Li, R.D. \& Baloch, H.A., Accelerated co-precipitation of lead, zinc and copper by carbon dioxide bubbling in alkaline municipal solid waste incinerator (MSWI) fly ash wash water. RSC Advances, 6, pp. 20173-20186, 2016. http://dx.doi.org/10.1039/C5RA23889G

[14] Bogush, A., Stegemann, J.A., Wood, I. \& Roy, A., Element composition and mineralogical characterisation of air pollution control residue from UK energy-from-waste facilities. Waste Management, 36, pp. 119-129, 2015. http://dx.doi.org/10.1016/j.wasman.2014.11.017

[15] Dabo, D., Raimbault, L., Badreddine, R., Chaurand, P., Rose, J. \& De Windt, L., Characterisation of glassy and heterogeneous cementing phases of municipal solid waste of incineration (MSWI) bottom ash. Australasian Institute of Mining and Metallurgy Publication Series, pp. 95-99, 2008.

[16] Dijkstra, J.J., van der Sloot, H.A. \& Comans, R.N.J., The leaching of major and trace elements from MSWI bottom ash as a function of $\mathrm{pH}$ and time. Applied Geochemistry, 21, pp. 335-351, 2006. http://dx.doi.org/10.1016/j.apgeochem.2005.11.003

[17] Piantonea, P., Bodenan, F. \& Chatelet-Snidaro, L., Mineralogical study of secondary mineral phases from weathered MSWI bottom ash: implications for the modelling and trapping of heavy metals. Applied Geochemistry, 19, pp. 1891-1904, 2004. http://dx.doi.org/10.1016/j.apgeochem.2004.05.006

[18] Santos, R.M., Mertens, G., Salman, M., Cizer, Ö. \& Van Gerven, T., Comparative study of ageing, heat treatment and accelerated carbonation for stabilization of municipal solid waste incineration bottom ash in view of reducing regulated heavy metal/metalloid leaching. Journal of Environmental Management, 128, pp. 807-821, 2013. http://dx.doi.org/10.1016/j.jenvman.2013.06.033

[19] Jiang, J., Chen, M., Zhang, Y. \& Xu, X., Pb stabilization in fresh fly ash from municipal solid waste incinerator using accelerated carbonation technology. Journal of Hazardous Materials, 161, pp. 1046-1051, 2009. http://dx.doi.org/10.1016/j.jhazmat.2008.04.051

[20] Yunmei, W., Takayuki, S., Amirhomayoun, S. \& Fumitake, T., Mineralogical characterization of municipal solid waste incineration bottom ash with an emphasis on heavy metal-bearing phases. Journal of Hazardous Materials, 187, pp. 534-543, 2011. http://dx.doi.org/10.1016/j.jhazmat.2011.01.070

[21] Brännvall, E., Andreas, L., Sjöblom, R., Diener, S. \& Lagerkvist, A., Factors influencing chemical and mineralogical changes in RDF Fly ashes during aging. Journal of Environmental Engineering, 140(3), 2014. http://dx.doi.org/10.1061/(ASCE)EE.1943-7870.0000802

[22] Shimaoka, T., Miyawaki, K., Soeda, M., Hanashima, M., Yoshida, T., Uchida, T., Gardner, K.H. \& Eighmy, T.T., Mechanisms for the aging-induced reduction of 
lead solubility in scrubber residues from municipal solid waste combustion. Waste Management \& Research, 20, pp. 90-98, 2002. http://dx.doi.org/10.1177/0734242X0202000110

[23] Ecke, H., Menad, N. \& Lagerkvist, A., Carbonation of municipal solid waste incineration fly ash and the impact on metal mobility. Journal of Environmental Engineering, 129, pp. 435-440, 2003. http://dx.doi.org/10.1061/(ASCE)0733-9372(2003)129:5(435)

[24] Funatsuki, A., Takaoka, M., Oshita, K. \& Takeda, N., Methods of determining lead speciation in fly ash by X-ray absorption fine-structure spectroscopy and a sequential extraction procedure. Analytical Sciences, 28(5), pp. 481-490, 2012.

http://dx.doi.org/10.2116/analsci.28.481

[25] Sjöblom, R., Mechanisms for scale containing zinc and lead on tubes in conjunction with incineration of recycled wood fuels (in Swedish: Hypoteser och mekanismer för bildning av beläggningar innehållande zink och bly i samband med förbränning av returträflis). Värmeforsk (now Energiforsk), Miljö- och förbränningsteknik, 734, 2001.

[26] Mihee, L., Gi-Chun, H., Ji-Whan, A. \& Kwang-Suk, Y., Environmental remediation and conversion of carbon dioxide (CO2) into useful green products by accelerated carbonation technology. International Journal of Environmental Research and Public Health, 7, pp. 203-228, 2010.

http://dx.doi.org/10.3390/ijerph7010203 